\title{
Draw a River (DAR) : An Art Therapy in Wilderness Therapy.
}

Dr Bheemaiah, Anil Kumar, Bheemaiah Corp (formerly A.B), Seattle W.A 98125

miyawaki@yopmail.com

\begin{abstract}
:
Welcome the future with an Amazon Drone Pad with a vinyl art wrap of an art piece on river restoration, complete with Signify LiFi based drone landing lights. The Paper illustrates the use of Gestalt, CBT and MBAT based art therapies as wilderness therapy in the understanding of Autopilot thinking in oneself. Experiential outdoor therapy is described in digital art used to promote river restoration in conjunction with future secure deliveries of camping logistic supplies by amazon drones. Towards this goal, the creation of art wraps for drone pads, with LiFi lights is presented in this paper.

Draw a River (DAR) is introduced as a form of Art Therapy, either in surreal automatism or symbolic automation The theme being of restoring rivers.
\end{abstract}

Keywords:

Vayu Vaidya, Amazon Delivery Drone Pads, Art Wrap, Gestalt, CBT, MBAT,https:/www.nps.gov/olym/learn/nature/elwha-ecosystem-restoration.htm

What:

Creation of Art Therapy for Gestalt, CBT and MBAT Art Therapies on the theme of River Restoration using digital media and surrealist automatism, as a means of secure resupply logistics, with the side effect of strong coding for animal rights.

How: off the shelf drone pads, large enough for Amazon Delivery Drones or other Drone infrastructure to land, are art wrapped with vinyl self adhesive medium, printed with digital art created by Art Therapy patients.

Why: Advocacy for river restoration, visible aerially, as both wilderness therapy and as an art presentation.

\section{Introduction.}

Gestalt art therapy(Ph.D. \& Amendt-Lyon, 2001 ) is a formal coding of gestalt elements, like the closure, figure and ground and a strong element of symmetry. CBT(Website, n.d.) adds psychoanalysis of simple cognitive behavioural therapy, in approximationism,(Bheemaiah, 2020b) 
leading to improvements in mental wellness in many common ailments, from depression, aggression, detoxification, anxiety and PTSD and Autism Spectrum. MBAT is a more recent contribution in the use of mindfulness in the coding of formal elements and automatism in understanding the Autopilot Thinking.(Wonfor, 2017) In a self exploration of the autopilot thinking in automatism, river restoration and the restoration of the balance and one's place in the elements, both natural and human is emphasized, ending the struggle in life, rendering much needed wellness to struggling youth in particular.
Fig: Digital art inlay using Paint3D of the digital art

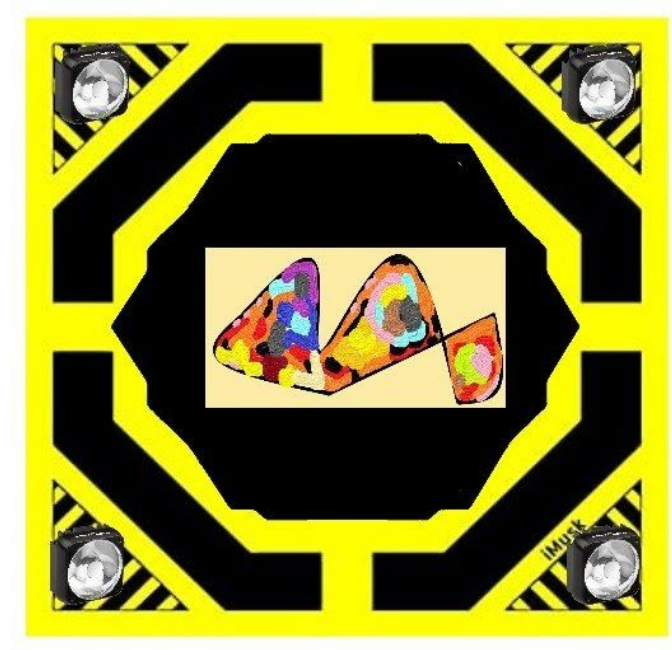

Restoring Rivers, by Dr Bheemaiah, on Deviant Art as MBAT based State Pod Automatism.(Bheemaiah, 2020a)

\section{Background.}

River Restoration, was primarily represented in a succession of victories in demolition of dams,(Elwha River Restoration - Olympic National Park (U.S. National Park Service), n.d.) the demolition of the enwiya dam, heralding a new era in the realization of the need for the replacement of outdated technologies like dams and other hydrology, with water body management, restoration and conservation measures. While healthy water bodies promote better therapeutic camping and wilderness therapy, the present art therapy as Gestalt, CBT and MBAT therapy help campaign for the restoration of water bodies 
worldwide through a portal with an aerial view in the form of drone landing pads.

Draw a river, is an additional therapy introduced as a form of river restoration art, as a river is drawn to represent the water element, the elimination of water pollution and the integration of northern and southern directions and eastern and western directions and the philosophy of Akiro Miyawaki in the natural restoration of forest cover and natural wealth, despite man made environmental disruptions.

Valuable side effects, in the form of fast and efficient resupply supplements present air dropping of resupplies, for less resource invasive resupply strategies.

The addition of LiFi landing lights adds emergency infrastructure and communications to the wilderness therapy practice.

\section{Discussion and Future Work.}

River Restoration, has been introduced in formal art therapy similar to drawing a road, as a means of art psychoanalysis and therapy in understanding naturalism and autopilot thinking. Future work involves a clinical study of group therapy and the analysis of the formal elements of Draw a River as River Restoration.

\section{References.}

Bheemaiah, A. K., Dr. (2020a). State Pod

Automatism as Art Therapy. In PsyArXiv.

Bheemaiah, A. K., Dr. (2020b).

Appoximationism as a new art form in Art

Therapy. In PsyArXiv.

Elwha River Restoration - Olympic National

Park (U.S. National Park Service). (n.d.).

Retrieved July 1, 2020, from

https://www.nps.gov/olym/learn/nature/elw

ha-ecosystem-restoration.htm

Ph.D., N. A.-L., \& Amendt-Lyon, N. (2001). Art

and Creativity in Gestalt Therapy. In

Gestalt Review (Vol. 5, Issue 4, p. 225).

https://doi.org/10.5325/gestaltreview.5.4.02

25

Website. (n.d.). 
https://doi.org/10.1002/9781118306543.ch7

Wonfor, D. (2017). Catalyst 14.

https://www.catalyst14.co.uk/blog/mindful ness-in-every-day-life-waking-up-from-aut omatic-pilot 